\title{
Connections with Coworkers on Social Network Sites: The Good, the Bad and the Ugly
}

\author{
Ariane Ollier-Malaterre, $\mathrm{PhD}$ \\ Université du Québec A Montréal \\ ollier.ariane@uqam.ca
}

\author{
Annie Foucreault \\ Université du Québec A Montréal \\ foucreault.annie1@gmail.com
}

\begin{abstract}
A large number of individuals are connected with their coworkers on social network sites (SNS) that are personal and professional (e.g., Facebook), with consequences on workplace relationships. Drawing on SNS, social identity and boundary management literatures, we surveyed 202 employees and found that coworkers' friendship-acts (e.g., liking, commenting) were positively associated with closeness to coworkers when coworkers were of the same age or older than the focal individual, and with organizational citizenship behaviors towards coworkers (OCBI) when coworkers were of the same age. Harmful behaviors from coworkers (e.g., disparaging comment) were negatively associated with closeness (but not with $O B C I)$ when coworkers were older than the focal individual. In addition, preferences for the segmentation of one's professional and personal roles moderated the relationship between coworkers' friendship-acts and OCBI (but not closeness) such that the positive relationship was stronger when the focal individual had low (vs. high) preferences for segmentation.
\end{abstract}

\section{Introduction}

Social network sites (SNS), which are web-based services on which individuals may create a public or semi-public profile, connect with other users with whom they share a connection, and view others' profiles and connections (Boyd \& Ellison, 2007), serve an important role for relationship development and maintenance [1]. SNS have moved from leisure to work [2]: while enterprise social media (ESM) are dedicated to workplace communications, public social network sites can focus on work (e.g., LinkedIn), personal life and leisure (e.g., dating sites), or bridge the personal and professional realms (e.g., Facebook, Twitter, Instagram, Google+, Youtube) [3].
On these latter sites, which we call integrative SNS, people may choose to connect with friends and family as well as with professional contacts [4-6]. In fact, as many as $58 \%$ of U.S. employees are connected on Facebook with coworkers and $40.5 \%$ with bosses [7]. These connections may serve work as well as social purposes, and represent the online equivalent of going out for drinks after a long work day [4]. As such, integrative SNS that blur the boundaries between personal and professional social worlds have become social spaces in which interactions may be consequential for interpersonal relationships at work.

One of the "enchanting affordances" [8] of integrative SNS is that they may help coworkers to see the whole person behind the coworker. As such, coworkers may build rich multiplex relationships in which they simultaneously enact work and nonwork roles and identities [9]. However, the blurring of the boundaries, or multiple audience issue [10] can also increase risks of harassment, confidentiality breaches discrimination [8, 11], privacy invasions [12, 13] and interpersonal surveillance $[14,15]$.

Although scholars have called for research examining the overlap of online and offline relationships [8], little work has examined how connections with coworkers on integrative SNS such as Facebook may change workplace relationships. Our paper sets out to understand how coworkers' friendship-acts online (e.g., liking a post, commenting on a post [16]), and harmful behaviors (e.g., posting an offending comment [17]), may affect two constructs that are central for interpersonal relationships at work and likely to be influenced by interactions on SNS: feelings of closeness with one's coworkers [18], and the interpersonal component of organizational citizenship behaviors (OCBI; [19]). Understanding these relationships is important because positive relationships at work and a professional image on SNS matter for professional reputations and careers [20], and because relationships at work drive team cohesion and performance $[21,22]$. 
In addition, we extend knowledge on the outcomes of SNS on relationships at work by identifying what the boundary conditions of these outcomes may be. Building on social identity theory [23, 24] and on research on SNS disclosures across generations of employees [25], we examine the moderating role of coworkers' age (dis)similarity [26]. We also draw on boundary management theory [27, 28] and identify individual preferences for segmentation or integration of work and nonwork roles [29] as another moderator. We test our model on a sample of 202 employees in a wide range of professional settings.

\section{Connexions with coworkers on integrative SNS}

There is research on the outcomes of SNS connections on social capital [30, 31], privacy loss [32], image management [33], mental overload [5], exhaustion [34], the socialization of new hires [35, 36], collaboration and knowledge sharing [2], learning [37], self-coping in the absence of unions [38], perceptions of organizational support [39], job performance [40, $41]$, and career consequences [20,42].

However, interpersonal relationships at work have not been the focus of much social media research, despite theoretical works and literature reviews outlining how connexions with coworkers may impact coworkers' warmth and competence judgments [6], friendship formation [43], and envy [44]. The empirical work that exists points out that SNS connexions play a role in fostering positive (i.e., respect, liking and $\mathrm{OCBI}$ ) and negative (i.e., disliking, loss of respect and envy) attitudes and behaviors at work [45, 46] as well as in workplace romantic relationships [47]. However, no research to date has examined what variables may moderate the relationship between SNS connexions and workplace outcomes, which we endeavor to investigate.

We focus on the relationship between coworkers' friendship-acts and harmful behaviors on integrative SNS and closeness and OCBI. Closeness at work refers to a sense of connection and bonding with coworkers that goes beyond mere work interactions [26, 48]. OBCI refers to discretionary extra-role behaviors not prescribed by the job and benefiting coworkers, such as assisting a coworker who has been absent or taking on additional work to help a coworker [19].

\subsection{Coworkers' friendship-acts, closeness and OCBI across age (dis)similarity}

Disclosure of information is one of the key components of relationship building [49]. Relatedly, the ease with which people can share and connect with others on SNS is one of the enchanting affordances that attract users to these sites [8]. Employees who open up to coworkers on integrative SNS and share details about their personal lives, thoughts, and desires indicate trust and allow coworkers who view their publications to discover common perspectives and behave in seemingly more authentic ways [18, 50, 51]. Therefore, exchange of information on SNS increases face-to-face interactions [52], intimacy [53] and perceived social support [54]. When they expose their whole personae rather than just their professional personae, employees may benefit from boundary crossovers that may enrich their relationships at work $[6,55]$, all the more than computer-mediated interactions tend to be more intimate than normal [56] compared to face-to-face interactions. Positivity and humor on SNS also increase feelings of connection [51]. In addition, affordances such as the "Like" button and its variations, and the ability to comment on publications convey that one is being acknowledged and appreciated, which may create positive emotions [35] and thus fuel closeness and OCBI. Furthermore, connecting on integrative SNS may be particularly helpful to get to know new coworkers. The "timeline" affordance of Facebook, for instance, gives access to an archive of chronologically displayed information [13] that may help identify topics of mutual interest and build common ground with coworkers [57], thus increasing closeness and OCBI.

However, we argue that age (dis)similarity influences the ways in which connexions with coworkers shape closeness and OCBI. Age consistently segregates and stratifies individuals in societies and work teams [58, 59]. Of interest to SNS disclosures, individuals of similar age share common characteristics and history that increase the similarity of their non-work-related experiences [60]. For instance, middle-aged employees are more likely to publish pictures of their young children, and older employees about caring for their elder parents. These common experiences outside the workplace, which are made more salient by integrative SNS, may highlight shared interests and therefore moderate the relationship between SNS connexions and closeness and OCBI. In addition, social norms regarding acceptable disclosure of information on SNS might differ across generations and life stages [61]. In particular, younger employees tend to have a more personal and expressive view of social media than older employees [62]. For instance, an older employee might not approve of a younger coworker sharing hundreds of personal photos on SNS, while the younger coworker might see the older coworker's profile as stodgy or boring. In other words, older coworkers may consider that the front stage 
workplace norms that they abide [63] should be upheld on SNS interactions, whereas younger coworkers may think that authentic back stage behaviors (e.g., casual language, dress, and behaviors) are appropriate. Given our reasoning above, we propose the following:

Hypothesis 1: When most coworkers are of the same age or older (vs. younger) than the focal individual, coworkers' friendship-acts on integrative SNS are positively associated with (a) closeness with coworkers and (b) OCBI.

\subsection{Harmful behaviors, closeness and OCBI across age (dis)similarity}

SNS also present less enchanting and even hurtful affordances [8], such that one may be offended by coworkers' publications or comments. First, an employee whose coworker ignores the connection request, or redirects him or her to a more professional site such as LinkedIn, may experience awkwardness in the relationship. S/he may also feel less close to the coworker and less prone to help him or her because the coworker just signaled distance in the relationship [6, 17]. Second, SNS postings by malevolent coworkers may tamper with an employee's online reputation, as when coworkers share negative opinions, photos and videos about the employee, the workplace, or the customers [17]. Such behaviors may downright damage relationships at work [17]. Third, an employee can be offended when a coworker shares facts and opinions about other employees, the workplace, or customers that the employee views as inappropriate [17]. This type of harmful behaviors may occur inadvertently as people on most SNS have an imagined audience in mind when they post [64], or an intended audience [51] that forgets about connections who do not frequently interact with them and are therefore invisible [13]. Fourth, hyper-intimacy may lead one to comment a publication in a more familiar way than in face-to-face, phone, chat or email interactions [56]. Such intrusive interactions may be perceived by coworkers as a norm [65] and a boundary [6] violation and be experienced as an invasion of privacy [5].

Older individuals are more likely, on average, to have attained higher tenure [66] and control over resources [67]. Therefore, younger coworkers are likely to feel vulnerable because they depend on older coworkers to access resources at work and maintain good standing. From this follows that harmful behaviors perpetrated by older coworkers are more likely to be negatively perceived by younger workers.

The second reason why harmful behaviors may have more negative outcomes when the focal person is younger is that older persons' identity, sense of competence and dignity are less threatened by antisocial behaviors than the younger persons' are [68]. In fact, older adults' emotional responses to social media requests from coworkers is lesser than younger adults'[69]. The lesser response may occur because older individuals become less emotionally invested in other people and more inner focused [70], and have a greater ability to express their affection for others even in conflict situations [71]. Therefore, we argue:

Hypothesis 2: When most coworkers are older than the focal individual, harmful behaviors from coworkers on integrative SNS are negatively associated with (a) closeness with one's coworkers and (b) OCBI.

\subsection{Boundary management preferences}

We argue that coworkers' friendship-acts on integrative SNS are more likely to increase closeness and OCBI for individuals who have low (vs. high) preferences for segmentation of work and nonwork roles. Boundaries between work and nonwork roles serve as mental fences that organize and simplify the environment [27, 28]. They may be temporal, spatial or relational. Individuals vary in the extent to which they prefer to integrate work and life -e.g., mixing friends and coworkers in family events, displaying family pictures at work- or to keep them separate -e.g., not answering coworkers' emails after working hours [72].

Such preferences are also enacted on integrative SNS: Individuals who feel pressured to accept requests from professional contacts but who prefer to segment work of nonwork roles use specific strategies: they censor the information they share [73], use a lowest common denominator approach [74], adjust their profile visibility [75], use privacy settings and nicknames to disclose different information to different individuals $[14,76]$, or create multiple profiles [77]. In fact, $58 \%$ of Facebook users restrict access to their profiles and $44 \%$ have removed content that others had published on them [78].

Individuals who have low preferences for segmentation are likely to be more comfortable with boundary spanning behaviors and more motivated to connect with coworkers [6]. Individuals who have high preferences for segmentation, on the other hand, may accept connection requests from coworkers so as to avoid offending them, yet they may not be receptive to their coworkers' comments and acknowledgments on SNS. They may also resent the loss of control over their boundaries [79] and therefore be less likely to feel closer or to be inclined to help the coworkers with whom they connect on SNS. Therefore, we propose: 
Hypothesis 3: Preferences for segmentation moderates the relationship between coworkers' friendship-acts on integrative SNS and (a) closeness and (b) OCBI such that these relationships are stronger for employees who have low (vs. high) preferences for the segmentation of their work and nonwork roles.

\section{Method}

\subsection{Sample}

A snowball and network sampling method [80] was used to collect our data, in line with our research objectives of understanding the influence of social interactions within an online social network [81]. An online questionnaire was distributed to respondents recruited on Facebook starting with authors' networks as well as open groups to leverage the representativeness of the Facebook population as a sample source [82]. Inclusion criteria were to be over 18 years of age, to be connected on Facebook with at least two coworkers, and to work 20 hours or more per week. A total of 299 participants volunteered, of which 252 met all the inclusion criteria. 48 were removed because of missing data, and 2 due to multivariate extreme values. In the final sample $(n=202)$, there was a majority of women $(63.9 \%)$, participants were 34.34 years old on average $(S D=11.3)$ and $50.2 \%$ had completed at least a bachelor's degree. They had had a Facebook account for 6.87 years on average $(S D=1.6)$ and worked in various industry sectors in Quebec, including health and social services (15.8\%), educational services (12.4\%), and professional, scientific, and technical services (9.9\%).

\subsection{Measures}

Coworkers' friendship-acts. A scale was developed for the purpose of this study. Participants were asked to indicate how frequently their coworkers performed the action indicated on Facebook (4 items: "like"your status, photos or videos", "comment your status, photos or videos", "share your status, photos or videos" and "send you private messages") on a scale from 1 (never) to 8 (every hour). This scale had been previously validated in French with an independent sample of 243 workers. The Cronbach alphas obtained in the independent sample $(\alpha=.92)$ as well as in the present study $(\mathrm{a}=.85)$ were both satisfactory.

Coworkers' harmful behaviors. Three subscales of the Work-related Social Media Questionnaire by Landers and Callan (2014) that specifically capture harmful behaviors were used; we retained the 5 items that relate to coworkers (as opposed to customers): disparaging others (2 items; e.g., "My coworkers have posted negative opinions about me on Facebook."; $\alpha=.90$; French $\alpha=.91)$, diminishing personal reputation (1 item; i.e., "My coworkers have posted photos, videos or content about me on Facebook that harmed my professional reputation") and relationship refusal (2 items; e.g., "It has felt awkward at work after I refused a connection on social media with someone at work"; $\alpha=.92$; French $\alpha=.79$ ). Items were adapted to refer to coworkers' behaviors on Facebook. The internal consistency of the French translation was satisfactory $(\mathrm{a}=.86)$.

Closeness. A subscale of psychological closeness [83] was adapted by replacing "relation" with "coworkers". The scale was translated into French and revised by two experts in the field. The internal consistency of the translation $(a=.91)$ is similar to the original study $(a=$ .93). Respondents were asked to indicate to what degree they agree with each statement (10 items; e.g., "How close are you to your coworkers", "How often do you talk about personal things with your coworkers") on a scale of 1 (strongly agree) to 7 (strongly disagree).

OCBI. Four items (e.g., "I listen to coworkers when they have to get something off their chest") of the OCBI subscale [84] were used. Participants were asked to indicate their level of agreement with each statement on a scale from 1 (strongly disagree) to 5 (strongly agree). The scale was also translated by one of the authors and revised by two experts. The internal consistency of this version $(a=.83)$ is similar to the original study $(\mathrm{a}=.93)$.

Age (dis)similarity was measured by asking participants if their coworkers were predominantly of the same age as themselves (1), younger (2) or older (3).

Preferences for segmentation. Kreiner's scale (2006; Segmentation Preference Scale) translated in French by anonymized reference (2016) was used. For each item (4 items; e.g., "I don't like work issues creeping into my home life."), participants indicated their level of agreement on a scale from 1 (strongly disagree) to 7 (strongly agree). The Cronbach's alpha $(\mathrm{a}=.89)$ was consistent with the one obtained in the anonymized reference (2016).

Control variables. We assessed potential confounding variables which may influence closeness with coworkers and OCBI: age, gender, education, industry sector, tenure, years on Facebook and proportion of coworkers who were been personal friends with the participants before they had worked together).

\section{Findings}




\subsection{Preliminary analyses}

Table 1 shows descriptive statistics as well as bivariate correlations. Since age $(r=-20, p=.005)$ and personal friends $(r=.16, p=.024)$ were related to closeness, we controlled for the effect of these variables on closeness.

Table 1. Means, standard deviations, and zero-order correlations for all study variables

\begin{tabular}{|c|c|c|c|c|c|c|c|c|c|c|c|c|c|c|}
\hline & Nhaan & $S D$ & 1 & 2 & 3 & 4 & 5 & 6 & 7 & 8 & 9 & 10 & 11 & 12 \\
\hline 1 . Gender & 1.64 & .48 & & & & & & & & & & & & \\
\hline 2 Age & 3434 & 1130 & .10 & & & & & & & & & & & \\
\hline 3. Level of etcation & 5.43 & 1.22 & .00 & $-27 \%$ & & & & & & & & & & \\
\hline 4. indatsy setior & 1226 & 6.60 &.$\infty$ &.$\infty$ & .07 & & & & & & & & & \\
\hline 5. Teuse & 8.53 & 8.01 & .03 & $63^{* *}$ & $.25 *$ & .01 & & & & & & & & \\
\hline 6. Years on Facebook & 7.87 & 1.60 & $17 \%$ & .23 & .01 & .00 & $.19 * *$ & & & & & & & \\
\hline 7. Personal friends & 1.44 & .56 & .10 & .08 & .11 & .04 & $.19 * *$ & .06 & & & & & & \\
\hline 8. Closeness & 5.26 & 97 & .06 & $.20^{* *}$ & 13 & .03 & .04 & .12 & $16^{* *}$ & & & & & \\
\hline $9.0 \mathrm{CBI}$ & 4.38 & .48 & .05 & .03 & .08 & .03 & .04 & .07 & .00 & 47** & & & & \\
\hline 10. Comoriters' triendstip-acts & 3.59 & 1.24 & .05 & .14 & .12 & .02 & $.15^{\circ}$ & .05 & $21 *$ & $30 * 4$ & $21 *$ & & & \\
\hline 11. Conuries' ham & 1.18 & $A 1$ & .01 & 01 & .08 & .03 & .02 & .09 & .07 & $.21 *$ & $-16^{* *}$ & 01 & & \\
\hline 12 Age (dissimilurity & 1.94 & 90 & . $19^{* *}$ & .37* & .08 & .02 & $-18^{* *}$ & .01 & $.15^{\circ}$ & .02 & .06 & $.16^{*}$ & .08 & \\
\hline 13. Pref for segmentatiox & 5.29 & 1.23 & .00 & 12 & .07 & .01 & .01 & .13 & -10 & $.21^{*}$ & .03 & .13 & .99 & .06 \\
\hline
\end{tabular}

Note. Spearman's correlation coefficients were used for ordinal data and Pearson's correlation coefficients for continuous variables. Gender = male (1), female (2); Education = no diploma (1) to (8) doctoral diploma; Industry sector $=22$ industry sectors according to the North American Industry Classification System Canada 2012; Personal friends = proportion of coworkers with whom participants had been personal friends with before they had worked together on a scale of none of my coworkers (1) to all my coworkers (4); $\mathrm{Ag}$ (dis)similarity $=$ coworkers were predominantly of the same age than the focal individual (1), younger (2), or older (3); $*=p<.05 ; * *=p<.01 ; * * *=p<.001$.

Using Mplus 7.31 software [85], we verified that the proposed model had five independent factors (i.e., coworkers' friendship acts on SNS, coworkers' harmful behaviors on SNS, closeness, OCBI, and preferences for segmentation) with a confirmatory factor analysis (CFA). For each latent variable, we fixed an item at 1.0 [86]. The fit indices from the CFA show that the five-factor model fits the data sufficiently well $\left(\chi^{2}(341)=634.59, p<.001\right.$, RMSEA $=.07[.06 ; .07], \mathrm{CFI}=.91, \mathrm{SRMR}=.06)[87]$ and that this model is superior to a four-factor models.

\subsection{Path analyses}

Path analyses were also conducted using Mplus 7.31 [85]. Independent variables (i.e., coworkers' friendship-acts and harmful behaviors) were standardized and two models were verified. Hypotheses 1a, 1b, 2a, and 2b were simultaneously verified in the first model using a multiple group analysis with age (dis)similarity as the grouping variable ( $n=89$ for same age; $n=37$ for younger, $n=$ 76 for older). Coworkers' friendship-acts and harmful behaviors were entered as independent variables and closeness and OCBI as dependent variables. Fit indices were $\operatorname{good}\left(\chi^{2}(6)=2.72, p=.843, \mathrm{RMSEA}=.00[.00\right.$; $.09], \mathrm{CFI}=1.00, \mathrm{SRMR}=.02)$.

As presented in Table 2, coworkers' friendship-acts were positively associated with closeness for employees whose coworkers were predominantly of the same age or older than themselves, but not for employees whose coworkers were predominantly younger, supporting hypothesis 1a. Coworkers' friendship-acts were positively associated with OCBI for employees whose coworkers were predominantly of the same age as themselves, but not for employees whose coworkers were predominantly younger or older, in partial support of hypothesis 1b. Coworkers' harmful behaviors were negatively associated with closeness for employees whose coworkers were predominantly older than themselves but not for employees whose coworkers were predominantly of the same age or younger, supporting hypothesis $2 \mathrm{a}$. Hypothesis 2b was not supported, as the relationship with coworkers' harmful behaviors and OCBI was not moderated by age (dis)similarity. A post-hoc regression analysis in SPSS indicated that coworkers' harmful behaviors decreased OCBI for employees of all ages $(\beta=-.16, p=.024 ; F(1,200)=5.17, p=.024)$ and explained $3 \%$ of the variance in OCBI.

Table 2. Path analysis model's results with age (dis)similarity as moderator (standardized coefficients)

\begin{tabular}{|c|c|c|c|c|c|c|c|c|c|c|c|c|}
\hline & \multicolumn{4}{|c|}{ Same age coworkers } & \multicolumn{4}{|c|}{ Younger coworkers } & \multicolumn{4}{|c|}{ Older coworkers } \\
\hline & \multicolumn{2}{|c|}{ Closeness } & \multicolumn{2}{|c|}{$\overline{O C B I}$} & \multicolumn{2}{|c|}{ Closeness } & \multicolumn{2}{|c|}{$\overline{O C B I}$} & \multicolumn{2}{|c|}{ Closeness } & \multicolumn{2}{|c|}{ OCBI } \\
\hline & Estim. & S.E. & Estim & S.E. & Estim & S.E. & Estim & S.E. & Estim. & S.E. & Estim & S.E. \\
\hline$\overline{\mathrm{Age}}$ & $-.24^{* *}$ & .08 & & & -.09 & .15 & & & -.15 & .09 & & \\
\hline Personal friends & .10 & .08 & & & .18 & .15 & & & .13 & .10 & & \\
\hline $\begin{array}{l}\text { Coworkers' friendship- } \\
\text { acts }\end{array}$ & $.42^{* * * *}$ & .08 & $.26^{* *}$ & .10 & .09 & .16 & .12 & .16 & $.27^{* * *}$ & .11 & .18 & .11 \\
\hline $\begin{array}{l}\text { Coworkers' } \\
\text { harmful behaviors }\end{array}$ & -.14 & .09 & -.19 & .10 & -.08 & .16 & -.18 & .16 & $-.38^{* * * *}$ & .09 & -.10 & .11 \\
\hline
\end{tabular}

Hypotheses $3 a$ and $3 b$ were verified in a second model. Standardized values of coworkers' friendshipacts and preferences for segmentation as well as the interaction term were entered in the model as independent variables, and closeness and OCBI as dependent variables. Fit indices indicated a sufficiently-fitting model $\left(\chi^{2}(2)=1.23, p=.542\right.$, RMSEA $=.00[.00 ; .12], \mathrm{CFI}=1.00$, SRMR $=.01)$. The upper bound of the confidence interval for the RMSEA was above the recommended value of .10 , but Kenny al. (2014) stated that this is a common statistical artifact in models with few parameters.

As shown in Figure 1 and Table 3, preferences for segmentation only moderated the relationship between coworkers' friendship-acts and OCBI. The simple effects indicate that coworkers' friendship-acts significantly and positively predicted OCBI for individuals who reported low preferences for segmentation $(t=3.09, p<.05)$ but not for those who have high preferences for segmentation $(t=.20, p=$ .844). These results invalidate hypothesis $3 \mathrm{a}$ and support hypothesis $3 b$. 
Table 3. Path analysis model's results with preferences for segmentation as moderator (standardized coefficients)

\begin{tabular}{|c|c|c|c|c|c|c|c|c|c|c|c|c|}
\hline & \multicolumn{4}{|c|}{ Same age coworkers } & \multicolumn{4}{|c|}{ Younger coworkers } & \multicolumn{4}{|c|}{ Older coworkers } \\
\hline & \multicolumn{2}{|c|}{ Closeness } & \multicolumn{2}{|c|}{ OCBI } & \multicolumn{2}{|c|}{ Closeness } & \multicolumn{2}{|c|}{ OCBI } & \multicolumn{2}{|c|}{ Closeness } & \multicolumn{2}{|c|}{ OCBI } \\
\hline & Estim. & S.E. & Estim & S.E. & Estim & S.E. & Estim & S.E. & Estim. & S.E. & Estim & S.E. \\
\hline$\overline{\text { Age }}$ & $-.24 * *$ & .08 & & & -.09 & .15 & & & -.15 & .09 & & \\
\hline Personal friends & .10 & .08 & & & .18 & .15 & & & .13 & .10 & & \\
\hline $\begin{array}{l}\text { Coworkers' friendship- } \\
\text { acts }\end{array}$ & $.42 * * *$ & .08 & $.26 * *$ & .10 & .09 & .16 & .12 & .16 & $.27^{* * *}$ & .11 & .18 & .11 \\
\hline $\begin{array}{l}\text { Coworkers' } \\
\text { harmful behaviors }\end{array}$ & -.14 & .09 & -.19 & .10 & -.08 & .16 & -.18 & .16 & $-.38 * * * *$ & .09 & -.10 & .11 \\
\hline
\end{tabular}

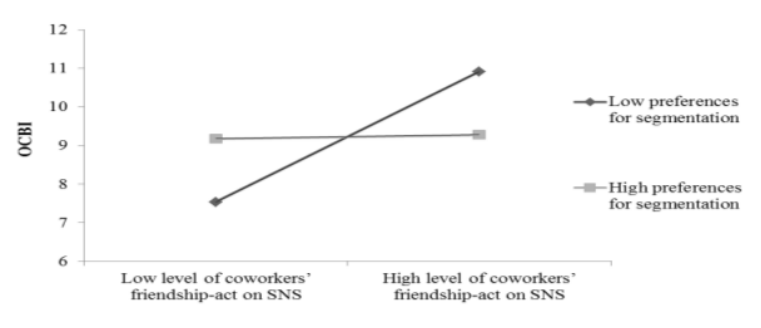

Figure 1. Interaction between coworkers' friendship-acts and segmentation preferences on OCBI

\section{Discussion}

Although an increasing number of individuals are connected with their coworkers on SNS that blend the personal and the professional (e.g., Facebook), and although theoretical works have called for more research on SNS connections and interpersonal relationships at work, little empirical research exists to date. The present study investigated the relationship between connections with coworkers on Facebook, closeness with coworkers and interpersonal organizational citizenship behaviors in a sample of 202 employees from a wide range of professional settings.

First, coworkers' friendship-acts on integrative SNS were positively associated with reporting feeling close with one's coworkers when most of these coworkers were of the same age or older than the focal individual, but were only positively associated with OCBI when most of these coworkers were of the same age as the focal individual. The closeness result is in line with social identity theory [24] and with the findings that homophily leads to interpersonal attraction [88]. The OCBI result, however, only partially supports our hypothesis, suggesting that OCBI towards older coworkers may occur independently from coworkers' friendship-acts on SNS. This may be explained by employees' dependence on older coworkers who, generally, enjoy greater control over resources in the workplace (e.g., knowledge and expertise) [67]: employees may be helping older coworkers for instrumental reasons, i.e., to gain access to these resources [89], rather than because of interactions with them on SNS.

Second, harmful behaviors from coworkers on integrative SNS were negatively associated with closeness with one's coworkers when most coworkers were older than the focal individual, but not when most coworkers were younger or of the same age. This is in line with our reasoning that younger coworkers are likely to feel vulnerable at work towards older coworkers [68]. However, harmful behaviors on SNS were negatively associated with OCBI for employees of all ages, suggesting that even older employees' motivation to go the extra mile for their coworkers may be eroded by disparaging behaviors on SNS [17].

Third, coworkers' friendship-acts on integrative SNS were more positively associated with OCBI for employees who had low (vs. high) preferences for the segmentation of their work and nonwork roles. In other words, integrators demonstrated more citizenship behaviors towards their coworkers who interacted with them on SNS, while segmentors' OCBI was not associated with such connections. This concurs with prior work which suggests that high segmentors may only reluctantly connect with coworkers on SNS [6, 20]. The finding that coworkers' friendship-acts were positively associated with closeness regardless of individuals' preferences for segmentation is intriguing. It suggests that connecting on Facebook leads to greater disclosure of one's own information and of one's coworkers', and that this mere disclosure increases one's sense of connection with coworkers, in line with social psychology findings $[49,90]$.

\subsection{Practical implications}

Our findings shed important light for interpersonal relationships at work. Although many organizations overlook public SNS because they fear intruding in their employees' private sphere, connexions with coworkers on both ESM and public SNS matter for interpersonal relationships and helping behaviors in the workplace which, in turn, drive team cohesion and performance $[21,22]$. These findings imply that organizations should consider public SNS in their organizational development and human resources programs. They could train employees and managers on the social media strategies likely to foster respect, liking and OCBI $[6,45]$, and make them aware of the role of age dynamics and boundary management preferences so that they are more sensitive when connecting with dissimilar coworkers.

\subsection{Limitations and future research}

While the present study contributes novel findings, the data are cross-sectional and therefore causal 
relationships cannot be assumed. A cross-lagged multilevel model assessing coworkers' SNS behaviors before measuring their influence on closeness and OCBI would yield additional insights. The data were also self-reported; in order to decrease concerns about common methods bias, future research should strive to assess the coworkers' SNS behaviors, and OCBI, by surveying the coworkers themselves. Lastly, other potential moderators of interest for future research are gender (dis)similarity, hierarchical level, salary differences and reciprocity between coworkers' friendship-acts online.

\section{Conclusion}

The present study points out positive and negative attitudes and behaviors associated with connecting with coworkers on SNS that blend professional and personal interactions. It also dives into the roles played by age (dis)similarity and preferences for the segmentation of work and nonwork roles. We hope that our findings will inspire a stream of research connecting communications, social psychology and management research.

\section{References}

[1] N.B. Ellison, C. Steinfield, and C. Lampe: "The benefits of Facebook "Friends:" Social capital and college students' use of online social network sites", Journal of Computer-Mediated Communication, 2007, 12, (4), pp. 1143-1168.

[2] P. Leonardi, and E. Vaast: "Social Media and their Affordances for Organizing: A Review and Agenda for Research", Academy of Management Annals, 2017, 11, (1), pp. 150-188.

[3] K. Hogberg: "Organizational Social Media: A Literature Review and Research Agenda". Proc. 51st Hawaii International Conference on System Sciences, Hawaii 2018 pp. 1864-1873.

[4] R. Berkowsky: "When you just cannot get away", Information, Communication \& Society, 2013, 16, (4), pp. 519-541.

[5] E. Bucher, C. Fieseler, and A. Suphan: "The stress potential of social media in the workplace", Information, Communication \& Society, 2013, 16, (10), pp. 1639-1667.

[6] A. Ollier-Malaterre, N.P. Rothbard, and J.M. Berg: "When worlds collide in cyberspace: How boundary work in online social networks impacts professional relationships", Academy of Management Review, 2013, 38, (4), pp. 645659.
[7] M. Duggan, N. Ellison, C. Lampe, A. Lenhart, and M. Madden: "Social Media Update 2014" (Pew Research Center, 2015).

[8] B. Miller, and P. Mundey: "Follow the rules and no one will get hurt: Performing boundary work to avoid negative interactions when using social network sites", Information, Communication \& Society, 2015, 18, (2), pp. $187-201$.

[9] C. Haythornthwaite: "Exploring multiplexity: Social network structures in a computer-supported distance learning class", The Information Society, 2001, 17, (3)

[10] B. Marder, A. Shankar, D. Houghton, and A. Joinson: "'What if My Mum Sees It?': Examination of visible brand interaction in the presence of a wider network", Information Technology \& People, 2017, 30, (1), pp. 210226.

[11] J. Peluchette, K.K. Van Eck, and J. Fertig: "“A Facebook 'friend' Request from the Boss: Too Close for Comfort?" ", Business Horizons, 2013, 56, (3), pp. 291-300.

[12] K. Lewis, J. Kaufman, and N. Christakis: "The taste for privacy: An analysis of college student privacy settings in an online social network", Journal of ComputerMediated Communication, 2008, 14, pp. 79-100.

[13] D. Boyd: "Social Network Sites: Public, Private, or What? http://kt.flexiblelearning.net.au/tkt2007/?page id=28", Knowledge Tree, 2007

[14] D. Trottier: "Interpersonal Surveillance on Social Media", Canadian Journal of Communication, 2012, 37, (2), pp. 319-332.

[15] B. Marder, A. Joinson, A. Shankar, and D. Houghton: "The extended 'chilling' effect of Facebook: The cold reality of ubiquitous social networking", Computers In Human Behavior, 2016, 60, pp. 582-592.

[16] P. Kordoutis, and E. Kourti: "Digital Friendship on Facebook and Analog Friendship Skills". Proc. European Conference on Social Media Research, Caen, France 2016 pp. 109-115.

[17] R.N. Landers, and R.C. Callan: "Validation of the beneficial and harmful work-related social media behavioral taxonomies: Development of the work-related social media questionnaire", Social Science Computer Review, 2014, 32, (5), pp. 628-646.

[18] H.H. Kelley, E. Berscheid, A. Christensen, J.H. Harvey, T.L. Huston, G. Levinger, E. McClintock, L.A. Peplau, and D.R. Peterson: "Close relationships" (Freeman, 1983. 1983). 
[19] D.W. Organ: "Organizational citizenship behavior: The good soldier syndrome" (Lexington Books 1988. 1988).

[20] A. Ollier-Malaterre, and N.P. Rothbard: "Social Media or Social Minefield? Surviving in the New Cyberspace Era", Organizational Dynamics, 2015, 44, (1), pp. 26-34.

[21] D.H. Gruenfeld, E.A. Mannix, K.Y. Williams, and M.A. Neale: "Group composition and decision making: How member familiarity and information distribution affect process and performance", Organizational Behavior And Human Decision Processes, 1996, 67, pp. p1-15.

[22] K.A. Jehn, and P.P. Shah: "Interpersonal relationships and task performance: An examination of mediating processes in friendship and acquaintance groups", Journal of Personality and Social Psychology, 1997, 72, pp. 775-790.

[23] B.E. Ashforth, and F. Mael: "Social identity theory and the organization", Academy of Management Review, 1989, 14, pp. 20-39.

[24] H. Tajfel, and J.C. Turner: "The social identity theory of intergroup behavior", in S. Worchel, and W.G. Aust (Eds.): "Psychology of intergroup relations" (NelsonHall, 1986), pp. p7-24.

[25] U. Pfeil, R. Arjan, and P. Zaphiris: "Age differences in online social networking $Đ$ A study of user profiles and the social capital divide among teenagers and older users in MySpace", Computers in Human Behavior, 2009, 25, (3), pp. 643-654.

[26] S.B. Bacharach, P.A. Bamberger, and D. Vashdi: "Diversity and homophily at work: Supportive relations among white and African-American peers", Acadamy of Management Journal, 2005, 48, pp. 619-644.

[27] B.E. Ashforth, G.E. Kreiner, and M. Fugate: "All in a day's work: Boundaries and micro role transitions", Academy of Management Review, 2000, 25, pp. 472-491.

[28] C. Nippert-Eng: "Home and work: Negotiating boundaries through everyday life" (University of Chicago Press., 1996. 1996).

[29] N.P. Rothbard, K.W. Phillips, and T.L. Dumas: "Managing Multiple Roles: Work-Family Policies and Individuals' Desires for Segmentation", Organization Science, 2005, 16, (3), pp. 243-258.

[30] N.B. Ellison, J. Vitak, R. Gray, and C. Lampe: "Cultivating Social Resources on Social Network Sites: Facebook Relationship Maintenance Behaviors and Their Role in Social Capital Processes", Journal of ComputerMediated Communication, 2014, 19, (4), pp. 855-870.
[31] J. Vitak, and N.B. Ellison: "'There's a network out there you might as well tap': Exploring the benefits of and barriers to exchanging informational and support-based resources on Facebook", New Media \& Society, 2013, 15, (2), pp. 243-259.

[32] Y. Alsarkal, N. Zhang, and H. Xu: "Your Privacy Is Your Friend's Privacy: Examining Interdependent Information Disclosure on Online Social Networks". Proc. 51st Hawaii International Conference on System Sciences (HICSS), Hawaii 2018 pp. 892-901.

[33] C. Fieseler, M. Meckel, and G. Ranzini: "Professional Personae - How Organizational Identification Shapes Online Identity in the Workplace", Journal of Computer-Mediated Communication, 2015, 20, (2), pp. 153170.

[34] W. van Zoonen, and R.E. Rice: "Paradoxical implications of personal social media use for work", New Technology, Work and Employment, 2017, 32, pp. 228-246.

[35] H. Koch, E. Gonzalez, and D. Leidner: "Bridging the Work/social Divide: The Emotional Response to Organizational Social Networking Sites", European Journal of Information Systems 2012, 21, (6), pp. 699-717.

[36] D. Leidner, H. Koch, and E. Gonzalez: "Assimilating Generation Y IT New Hires into USAA's Workforce: The Role of an Enterprise 2.0 System", MIS Quarterly Executive, 2010, 9, (4), pp. 229-242.

[37] T. van Puijenbroek, V. Poell, R. Timmerman, and B. Kroon: "The effect of social media use on work-related learning", Journal of Computer Assisted Learning 2014, 30, (2), pp. 159-172.

[38] N. Cohen, and J. Richards: "'I didn't feel like I was alone anymore': Evaluating self-organised employee coping practices conducted via Facebook", New Technology, Work And Employment, 2015, 30, (3), pp. 222-236.

[39] G. Schmidt, A. Lelchook, and J. Martin: "The relationship between social media co-worker connections and work-related attitudes", Computers In Human Behavior, 2016, 55, pp. 439-445.

[40] P. Charoensukmongkol: "Effects of Support and Job Demands on Social Media Use and Work Outcomes", Computers in Human Behavior, 2014, 36, pp. 340-349.

[41] H. Ali-Hassan, D. Nevo, and M. Wade: "Linking dimensions of social media use to job performance: The role of social capital", Journal of Strategic Information Systems, 2015, 24, (2), pp. 65-89.

[42] S. Dutta: "What's your personal social media strategy?", Harvard Business Review, 2010, Nov, pp. 127130. 
[43] J. Pillemer, and N.P. Rothbard: "Friends Without Benefits: Understanding the Dark Sides of Workplace Friendship", Academy of Management Review, In press

[44] L. Wallace, M. Markentin, and I. Benbazat: "How Do You Handle It? Developing a Theory of Facebook Affordances and Envy". Proc. 51st Hawaii International Conference on System Sciences (HICSS), Hawaii2018

[45] A. Ollier-Malaterre, and K. Luneau-de Serre: "Connecting with Coworkers on Social Network Sites: Strategies, Social Norms and Outcomes on Work Relationships,". Proc. Hawaii International Conference on Systems Sciences (HICSS), Hawai 2018 pp. 441-450.

[46] A. Batenburg, and J. Bartels: "Keeping up online appearances: How self-disclosure on Facebook affects perceived respect and likability in the professional context", Computers in Human Behavior, 2017, 74, pp. 265-276.

[47] R.L. Cowan, and S.M. Horan: "Understanding Information and Communication Technology Use in Workplace Romance Escalation and De-Escalation", International Journal of Business Communication, In press

[48] T.L. Dumas, K.W. Phillips, and N.P. Rothbard: "Getting Closer at the Company Party: Integration Experiences, Racial Dissimilarity, and Workplace Relationships, Organization Science", Organization Science, 2013, 24, (5), pp. 1377-1401.

[49] N.L. Collins, and L.C. Miller: "Self-disclosure and liking: A meta-analytic review", Psychological Bulletin, 1994, 116, pp. 457-475.

[50] A.M. Ledbetter, J.P. Mazer, J.M. DeGroot, K.R. Meyer, M. Yuping, and B. Swafford: "Attitudes toward online social connection and self-disclosure as predictors of Facebook communication and relational closeness", Communication Research, 2011, 38, (1), pp. 27-53.

[51] S. Utz: "The function of self-disclosure on social network sites: Not only intimate, but also positive and entertaining self-disclosures increase the feeling of connection", Computers in Human Behavior, 2015, 45, pp. $1-$ 10 .

[52] T. Dienlin, P.K. Masur, and S. Trepte: "Reinforcement or Displacement? The Reciprocity of FtF, IM, and SNS Communication and Their Effects on Loneliness and Life Satisfaction", Journal of ComputerMediated Communication, 2017, 22, (2), pp. 71-87.

[53] N. Park, B. Jin, and S.A. Jin: "Effects of selfdisclosure on relational intimacy in Facebook", Computers in Human Behavior, 2011, 27, (5), pp. 1974-1983.

[54] M. Seo, K, J., and H. Yang: "Frequent interaction and fast feedback predict perceived social support: Using crawled and self-reported data of Facebook users", Journal of Computer-Mediated Communication, 2016, 21, (4), pp. 282297.

[55] N.P. Rothbard, and L. Ramarajan: "Checking your identities at the door: Positive relationships between nonwork and work identities", in L.M. Roberts, and J.E. Dutton (Eds.): "Exploring positive identities and organizations: Building a theoretical and research foundation" (Routledge, 2009), pp. $125-148$.

[56] J.B. Walther: "Computer-mediated communication: Impersonal, interpersonal, and hyperpersonal interaction", Communication Research, 1996, 23, pp. 3-43.

[57] J.M. Dimicco, and D.R. Millen: "Identity management: multiple presentations of self in Facebook", in G. '07 (Ed.): "Proceedings of the 2007 international ACM conference on Supporting group work" (Association of Computing Machinery., 2007), pp. 383-386.

[58] C.M. Riordan, and L.M. Shore: "Demographic diversity and employee attitudes: An empirical examination of relational demography within work units", Journal of Applied Psychology, 1997, 82, pp. 342-358.

[59] S.L. Feld: "Social structural determinants of similarity among associates", American Sociological Review, 1982, 47, (6), pp. 797-801.

[60] T.R. Zenger, and B.S. Lawrence: "Organizational demography: The differential effects of age and tenure distributions on technical communication", Academy of Management journal, 1989, 32, (2), pp. 353-376.

[61] U. Pfeil, R. Arjan, and P. Zaphiris: "Age differences in online social networking-A study of user profiles and the social capital divide among teenagers and older users in MySpace", Computers in Human Behavior, 2009, 25, (3), pp. 643-654.

[62] J.W. Treem, S.L. Dailey, C.S. Pierce, and P.M. Leonardi: "Bringing Technological Frames to Work: How Previous Experience with Social Media Shapes the Technology's Meaning in an Organization", Journal of Communication, 2015, 65, (2), pp. 396-422.

[63] E. Goffman: "The Presentation of self in everyday life" (Doubleday Anchor Books, 1959. 1959).

[64] E. Litt: "Knock, Knock. Who's There? The Imagined Audience", Journal of Broadcasting \& Electronic Media, 2012, 56, (3), pp. 330-345.

[65] C. McLaughlin, and J. Vitak: "Norm evolution and violation on Facebook", New media \& society, 2011, 14, (2), pp. 299-315. 
[66] B.o.L. Statistics: "Employee tenure summary", in Editor (Ed.)^(Eds.): "Book Employee tenure summary" (2016, edn.), pp.

[67] T.M. Brimeyer, R. Perrucci, and S.M. Wadsworth: "Age, Tenure, Resources for Control, and Organizational Commitment*", Social Science Quarterly, 2010, 91, (2), pp. 511-530.

[68] K. Aquino, and S. Douglas: "Identity threat and antisocial behavior in organizations: The moderating effects of individual differences, aggressive modeling, and hierarchical status", Organizational Behavior and Human Decision Processes, 2003, 90, (1), pp. 195-208.

[69] C. Archer-Brown, B. Marder, T. Calvard, and T. Kowalski: "Hybrid social media: employees' use of a boundary-spanning technology", New Technology, Work and Employment, 2018, 33, (1), pp. 74-93.

[70] E. Cumming, and W. Henry: "Growing old: The process of disengagement" (Basic Books, 1961. 1961).

[71] L.L. Carstensen: "Social and emotional patterns in adulthood: Support for socioemotional selectivity theory", Psychology and Aging, 1992, 7, (3), pp. 331-338.

[72] G.E. Kreiner: "Consequences of work-home segmentation or integration: a person-environment fit perspective", Journal of Organizational Behavior, 2006, 27, (4), pp. 485-507.

[73] M. Skeels, and J. Grudin: "When Social Networks Cross Boundaries: A Case Study of Workplace Use of Facebook and LinkedIn", Proceedings Group 2009, Acm Press, 2009, pp. 95-104.

[74] B. Hogan: "The Presentation of Self in the Age of Social Media: Distinguishing Performances and Exhibitions Online", Bulletin of Science, Technology \& Society, 2010, 30, (6), pp. 377-386.

[75] Z. Tufekci: "Can you see me now? Audience and disclosure management in online social network sites", Bulletin Of Science And Technology Studies, 2008, 28, (1), pp. 20-36.

[76] J. Donath, and D. Boyd: "Public displays of connection", BT Technology Journal, 2004, 22, (4), pp. 7182.

[77] F. Stutzman, and W. Hartzog: "Boundary Regulation in Social Media": "Proceedings of ACM Conference on Computer Supported Cooperative Work" (Erlbaum, 2012), pp. 769-778.

[78] M. Madden: "Privacy management on social media sites" (Pew Internet, 2012).
[79] A. Foucreault, A. Ollier-Malaterre, and J. Ménard: "Organizational culture and work-life integration: A barrier to employees' respite?", The International Journal of Human Resource Management, 2016, pp. 1-21.

[80] L.A. Goodman: "Snowball sampling", The Annals of Mathematical Statistics, 1961, 32, (1), pp. 148-170.

[81] R.N. Landers, and T.S. Behrend: "An inconvenient truth: Arbitrary distinctions between organizational, mechanical turk, and other convenience samples", Industrial And Organizational Psychology: Perspectives On Science And Practice, 2015, 8, (2), pp. 142-164.

[82] M. Kosinski, S.C. Matz, S.D. Gosling, V. Popov, and D. Stillwell: "Facebook as a research tool for the social sciences: Opportunities, challenges, ethical considerations, and practical guidelines", American Psychologist, 2015, 70, pp. 543-556.

[83] A.L. Vangelisti, and J.P. Caughlin: "Revealing family secrets: The influence of topic, function, and relationships", Journal of Social and Personal Relationships, 1997, 14, (5), pp. 679-705.

[84] R.P. Settoon, and K.W. Mossholder: "Relationship quality and relationship context as antecedents of person-and task-focused interpersonal citizenship behavior", Journal of Applied Psychology, 2002, 87, (2), pp. 255-267.

[85] B.O. Muthén, and L.K. Muthén: "Mplus User's guide " (Muthén \& Muthén, 2012, Seventh Edition edn. 2012).

[86] J. Wang, and X. Wang: "Structural equation modeling: Applications using Mplus" (John Wiley \& Sons, 2012. 2012).

[87] D.A. Kenny, B. Kaniskan, and D.B. McCoach: "The performance of RMSEA in models with small degrees of freedom", Sociological Methods \& Research, 2014, pp. 122.

[88] D. Byrne: "The Attraction Paradigm" (Academic Press, 1971. 1971).

[89] P. Chattopadhyay, M. Tluchowska, and E. George: "Identifying the ingroup: A closer look at the influence of demographic dissimilarity on social identity", Academy of Management Review, 2004, 29, pp. 180-202.

[90] N. Kashian, J.W. Jang, S.Y. Shin, Y. Dai, and J.B. Walther: "Self-disclosure and liking in computer-mediated communication", Computers in Human Behavior, 2017, 71, pp. 275-283.

Acknowledgments: This research was supported by the Social Sciences and Humanities Research Council of Canada. We thank Cassy Pelletier for collecting the data. 